\title{
A Polyborate Coated Cellulose Composite Separator for High Performance Lithium Ion Batteries
}

\author{
Guoliang Ding, Bingsheng Qin, Zhihong Liu, ${ }^{\mathrm{Z}}$ Jianjun Zhang, Bo Zhang, Pu Hu, \\ Chuanjian Zhang, Gaojie Xu, Jianhua Yao, and Guanglei Cui ${ }^{\mathrm{Z}}$
}

Qingdao Industrial Energy Storage Technology Institute, Qingdao Institute of Bioenergy and Bioprocess Technology, Chinese Academy of Sciences, Qingdao 266101, People's Republic of China

\begin{abstract}
In this paper, a single ion polymer electrolyte enhanced cellulose nonwoven separator has been successfully explored via a dip-coating process for high-performance lithium ion battery. The single ion polymer electrolyte was comprised of polymeric lithium tartaric acid borate salt (PLTB) and polyvinylidene fluoride-co-hexafluoropropylene (PVDF-HFP). This single ion polymer electrolyte enhanced cellulose composite separator exhibited higher ionic conductivity, good flame retardancy and superior thermal resistance compared to the commercial polypropylene (PP) separator. Moreover, the composite separator at room temperature possessed lithium ion transference number $\left(\mathrm{t}_{\mathrm{Li}}{ }^{+}\right)$of 0.48 , which was higher than that using the pristine cellulose nonwoven $(0.31)$. Furthermore, it was demonstrated that the lithium cobalt oxide $\left(\mathrm{LiCoO}_{2}\right) /$ graphite cell with the composite separator delivered superior rate capability and better cycling performance than those with PP separator. These fascinating characteristics would endow this composite nonwoven a promising separator for high-performance lithium ion battery.
\end{abstract}

(c) 2015 The Electrochemical Society. [DOI: 10.1149/2.0261506jes] All rights reserved.

Manuscript submitted December 30, 2014; revised manuscript received February 13, 2015. Published February 24, 2015.

Lithium ion batteries have drawn extensive attention as high power sources for portable electronic devices such as smart phones, laptop computers and so on. ${ }^{1-7}$ Recently, lithium ion batteries are becoming promising power sources for hybrid electric vehicles (HEVs), plug-in hybrid electric vehicles (PHEVs) and electric vehicles (EVs). ${ }^{8-11}$ In lithium ion batteries, the separator plays a vital role in isolating the cathode from the anode, which is crucial to the battery safety. ${ }^{12,13}$ The separator should be robust to avoid internal short circuit between the cathode and anode thus to improve battery safety. ${ }^{12}$ Polyolefin-based separators have been extensively used as major separators for lithium ion battery. ${ }^{14-18}$ However, such separators suffered from serious thermal shrinkage at elevated temperatures when the battery was running at high charge/discharge current or under abused conditions. ${ }^{19-22}$ So it is imperative to develop high performance separators with improved thermal dimensional stability and enhanced battery performance.

Cellulose with excellent thermal stability is one of the most abundant, renewable natural polymers. ${ }^{23-26}$ Recently, cellulose and its derivatives have been explored in lithium ion battery for the production of electrodes, separators or reinforcing agents in polymeric electrolytes. ${ }^{24}$ Particularly, cellulose based separators can be fabricated by a facile and low-cost papermaking process in our lab. ${ }^{24,25}$ However, these cellulose based separators still have some disadvantages such as large-sized pores and flammability, which are hazardous to the battery safety. ${ }^{27}$ In order to enhance battery safety characteristics, cellulose-based composite separators were explored by coating inorganic nanoparticles or compositing retardant and other high performance polymers. ${ }^{12,20,25}$

Recently we developed a single-ion conducting lithium salt (PLTB, seen in Scheme 1), which was possessed of boron as central atom, surrounded by four oxygen ligands to form a delocalized system. ${ }^{28}$ The molecular configuration was helpful to delocalize the negative charge of the central ion, and the anion became more thermodynamically stable. The synthesis of PLTB via a one-pot aqueous reaction was cost-effective owing to abundant tartaric acid from biomass. The PLTB was demonstrated to possess high lithium ion transference number (0.91), enhanced ionic conductivity and thermal stability. ${ }^{28}$ The PVDF-HFP polymer is a well-known gel polymer electrolyte for use in rechargeable Li-ion batteries. ${ }^{29}$ It behaved as a substrate and framework for dispersing the PLTB. In addition, PVDF-HFP performed as a binder to integrate the PLTB onto the surface of the composite separator. Herein, the single ion polymer electrolyte (SPE) enhanced cellulose nonwoven separator (SPEC) has been successfully explored by a dip-coating process. It was expected that such renewable SPEC composite separator could possess desirable thermal behavior, higher ionic conductivity and electrochemical stability.

\section{Experimental}

Preparation of the SPEC separator- The procedure for the synthesis of PLTB was presented in our previous work. ${ }^{28}$ The coating solution consisted of PLTB, PVDF-HFP and NMP (10/10/80, w/w/w). The cellulose membrane $(25 \mu \mathrm{m})$ was fabricated via a facile and costeffective papermaking process, which was also previously reported. ${ }^{25}$ The pristine cellulose membrane was then immersed in the coating solution by a dip-coating process. The PLTB@PVDF-HFP solution soaked cellulose nonwoven was then dried at $120^{\circ} \mathrm{C}$ for 5 hours in vacuum to remove residue NMP. The final thickness of SPEC was about $30 \mu \mathrm{m}$. The weight ratio of PLTB@PVDF-HFP to supporting cellulose membrane is $1 / 6(\mathrm{w} / \mathrm{w})$.

Characterization of SPEC separator- The chemical structure of the membranes was characterized by Fourier transform infrared spectroscopy (FT-IR, Bruker VERTEX 70). Thermal stability of the separators was tested in an oven at $150^{\circ} \mathrm{C}$ for $0.5 \mathrm{~h}$. The thermal behaviors were evaluated by a differential scanning calorimeter (Diamond DSC, PerkinElmer) ranging from $50^{\circ} \mathrm{C}$ to $300^{\circ} \mathrm{C}$ at $10^{\circ} \mathrm{C} \mathrm{min}{ }^{-1}$ under a $\mathrm{N}_{2}$ atmosphere. The surface morphology of separators was observed by a Hitachi S-4800 field emission scanning electron microscope (SEM). X-ray diffraction (XRD) patterns of samples were recorded using a Bruker-AXS micro-diffractometer (D8 ADVANCE) with $\mathrm{Cu}-\mathrm{Ka} \cdot$ radiation $(\lambda=1.5406 \AA)$ from $5^{\circ}$ to $80^{\circ}$ at a scanning speed of $0.33^{\circ} \mathrm{min}^{-1}$. The LOI values were determined using a JF-3 type instrument (China). Specimens of dimensions $100 \mathrm{~mm} * 37 \mathrm{~mm} * 2 \mathrm{~mm}$ were used for all the tests. The air permeability of the separator was examined with a Gurley densometer (4110N, Gurley) by measuring the time for air to pass through a determined volume $(100 \mathrm{cc})$. The porosity of the separators was determined using n-butanol uptake method. For this purpose, the mass of the separators was measured before

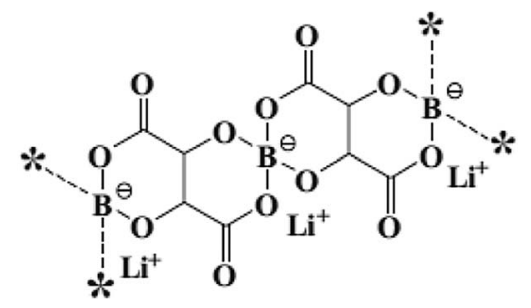


and after immersion in n-butanol for $2 \mathrm{hrs}$. The porosity of the membrane was calculated using the equation: porosity $=\left(\mathrm{m}_{\mathrm{b}} / \rho_{\mathrm{b}}\right) /\left(\mathrm{m}_{\mathrm{b}} / \rho_{\mathrm{b}}\right.$ $\left.+\mathrm{m}_{\mathrm{p}} / \rho_{\mathrm{p}}\right) \times 100 \%$, where $\mathrm{m}_{\mathrm{b}}$ and $\mathrm{m}_{\mathrm{p}}$ are the mass of $\mathrm{n}$-butanol and the separator, $\rho_{\mathrm{b}}$ and $\rho_{\mathrm{p}}$ are the density of $\mathrm{n}$-butanol and the separator, respectively. Meanwhile we used density of cellulose $\left(1.5 \mathrm{~g} / \mathrm{cm}^{3}\right)$ to calculate the porosity of cellulose nonwoven. The electrolyte uptake was obtained by measuring the weight of separator before and after soaking in liquid electrolyte for $2 \mathrm{hrs}$ and then calculated using following equation. Electrolyte uptake $=\left(\mathrm{W}_{\mathrm{f}}-\mathrm{W}_{\mathrm{i}}\right) / \mathrm{W}_{\mathrm{i}} \times 100 \%$, where $\mathrm{W}_{\mathrm{i}}$ and $\mathrm{W}_{\mathrm{f}}$ are the weight of the separator before and after soaking in the liquid electrolyte, respectively.

Electrochemical Measurements. - For the measurement of electrochemical performance, a liquid electrolyte of $1 \mathrm{M} \mathrm{LiPF}_{6}$ in EC/DMC (1/1, v/v) was employed. The ionic conductivity of separators between two stainless-steel plate electrodes was obtained by an AC impedance analysis using a Zahner Zennium electrochemical working station over a frequency range of $1-10^{6} \mathrm{~Hz}$ with a perturbation amplitude of $10 \mathrm{mV}$. Then the ionic conductivity could be calculated from bulk resistance with the equation: $\sigma=\mathrm{L} / \mathrm{AR}$, where $\mathrm{L}$ and A were the thickness and the geometric area of the separator, respectively, while $\mathrm{R}$ was the total resistance of the electrolyte across the membranes. Lithium ion transference number was measured according to the method described by Evants et al. ${ }^{30}$ The method involved sandwiching the sample membrane in both lithium electrodes. After having measured the total initial resistance by $\mathrm{AC}$ impedance, a DC potential of $10 \mathrm{mV}$ was applied until a steady state was reached. Finally, the resistance was again measured by AC impedance, $\mathrm{t}^{+}=$ $\mathrm{I}_{\mathrm{s}}\left(\Delta \mathrm{V}-\mathrm{I}_{\mathrm{o}} \mathrm{R}_{\mathrm{o}}{ }^{\mathrm{el}}\right) /\left[\mathrm{I}_{\mathrm{o}}\left(\Delta \mathrm{V}-\mathrm{I}_{\mathrm{s}} \mathrm{R}_{\mathrm{s}}{ }^{\mathrm{el}}\right)\right]$, Where $\mathrm{t}^{+}$is the cationic transference number, $\Delta \mathrm{V}$ is the potential applied across the cell, $\mathrm{R}_{\mathrm{o}}{ }^{\mathrm{el}}$ and $\mathrm{R}_{\mathrm{s}}{ }^{\mathrm{el}}$ are the initial and steady-state resistances of the passivating layers on the $\mathrm{Li}$ electrode and $\mathrm{I}_{\mathrm{o}}$ and $\mathrm{I}_{\mathrm{s}}$ are the initial and steady-state currents. The dependence of ionic conductivity on temperature can be reasonably fitted by the following equation: $\sigma=\mathrm{A} \exp (-\mathrm{Ea} / \mathrm{RT})$, where $\mathrm{A}$ is the pre-exponential factor and $\mathrm{Ea}$ is the activation energy.

A unit cell (2032-type coin) was assembled by sandwiching a separator between a natural graphite anode (natural graphite/carbon black/CMC/SBR, 93/5/1.25/0.75, w/w/w/w, around $8.79 \mathrm{mg} \mathrm{cm}^{-2}$ active material on copper metal foil disk, $\Phi=14 \mathrm{~mm}$ ) and a $\mathrm{LiCoO}_{2}$ cathode $\left(\mathrm{LiCoO}_{2} /\right.$ carbon black/PVDF, 90/5/5, w/w/w, around 18.65 $\mathrm{mg} \mathrm{cm}{ }^{-2}$ active material on aluminum metal foil disk, $\Phi=12 \mathrm{~mm}$ ), and then activated by filling it with the liquid electrolyte of $1 \mathrm{M} \mathrm{LiPF}_{6}$ in EC/DMC $(1 / 1, v / v)$. All cells were assembled in an argon-filled glove box. The charge/discharge performance was evaluated under a constant charge/discharge current and constant voltage charge along with the discharge densities were varied form $0.2 \mathrm{C}\left(0.35 \mathrm{~mA} \mathrm{~cm}{ }^{-2}\right)$ to $4.0 \mathrm{C}\left(7.0 \mathrm{~mA} \mathrm{~cm}^{-2}\right)$ for rate capability and $0.5 \mathrm{C}\left(0.88 \mathrm{~mA} \mathrm{~cm}^{-2}\right)$ for cycle test.

\section{Results and Discussion}

Typical SEM images of the pristine cellulose nonwoven and the SPEC separator were shown in Figure 1. It was observed in Figure 1a that the pristine cellulose nonwoven consisted of randomly arranged fibers with diameters about $0.2 \sim 2.0 \mu \mathrm{m}$ and it possessed excessively
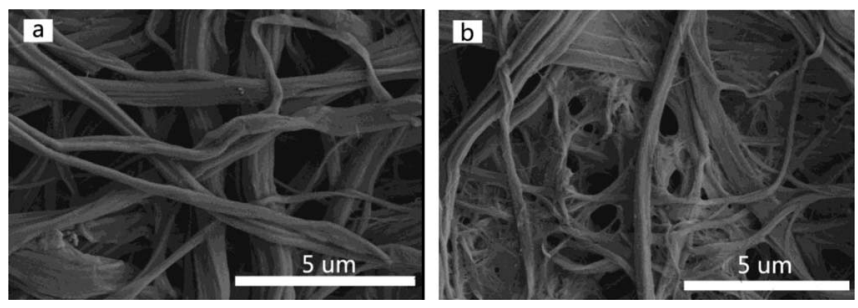

Figure 1. Typical SEM micrographs of (a) the pristine cellulose nonwoven and (b) the dry SPEC separator.

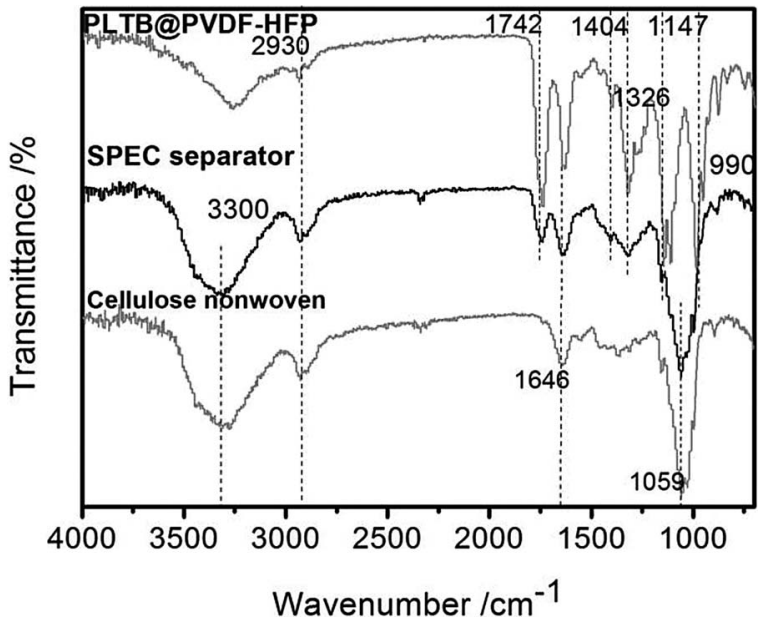

Figure 2. IR spectra of the PLTB @ PVDF-HFP, the pristine cellulose nonwoven and the dry SPEC separator.

large-sized pores ( $>2 \mu \mathrm{m}$ ), which was not beneficial to maintain the open circuit voltage due to self-discharge. And then we put PVDFHFP and PLTB single ion conductor into the cellulose nanofibers. As shown in Figure 1b, the pore diameter of the SPEC separator was about $1 \mu \mathrm{m}$. The well interconnected microporous structure between the interlaced microfibers was expected to suppress the growth of lithium dendrites and the micro short-circuit between cathode and anode, which can ensure an improved safety and battery performance.

Figure 2 depicted the IR spectra of the PLTB@PVDF-HFP, the pristine cellulose nonwoven and the SPEC separator. The absorption peaks of PLTB@PVDF-HFP were situated at 2930, 1742, 1635, $1404,1326,1147,839$ and $751 \mathrm{~cm}^{-1}$, which were assigned to $-\mathrm{CH}_{2}$ stretching, $\mathrm{C}=\mathrm{O}$ stretching, $\mathrm{C}-\mathrm{C}$ stretching, $-\mathrm{CH}_{2}$ - deformation, $\mathrm{B}-\mathrm{O}$ anti-symmetric stretching, -C-O- stretching and $-\mathrm{CF}_{2}$ - bending and skeletal bending, respectively. ${ }^{13,28}$ The typical peaks of cellulose were situated at 3300, 2929, 1646 and $1059 \mathrm{~cm}^{-1}$, attributing to $-\mathrm{O}-\mathrm{H}$ stretching, C-H stretching, C-C stretching and -C-O- stretching, respectively. The presence of all typical peaks of PLTB@PVDF-HFP and cellulose in the spectra of the SPEC separator indicated that the composite separator was successfully prepared by the dip-coating process.

Figure 3 showed the XRD patterns of SPEC separator, cellulose nonwoven, pure PLTB, pure PVDF-HFP copolymer and solid polymer electrolyte PLTB@PVDF-HFP. The XRD pattern of pure PLTB

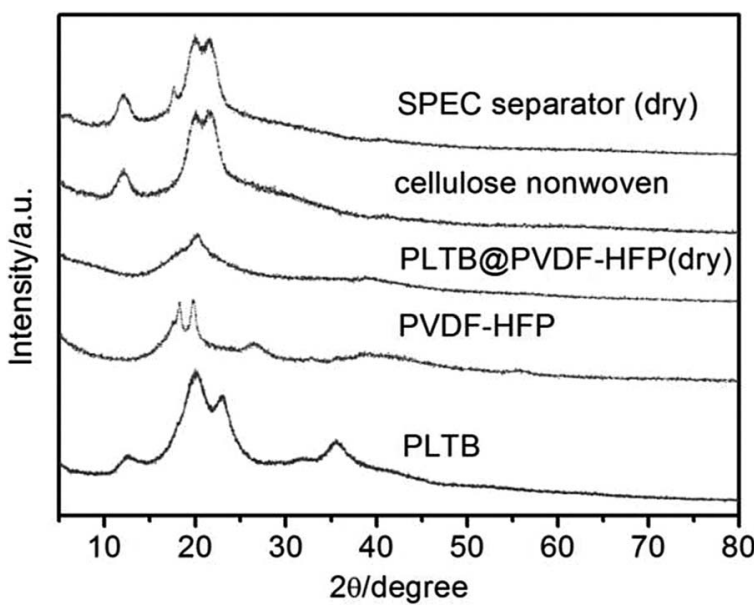

Figure 3. XRD patterns of dry SPEC separator, cellulose nonwoven, PLTB, PVDF-HFP and dry PLTB@PVDF-HFP. 


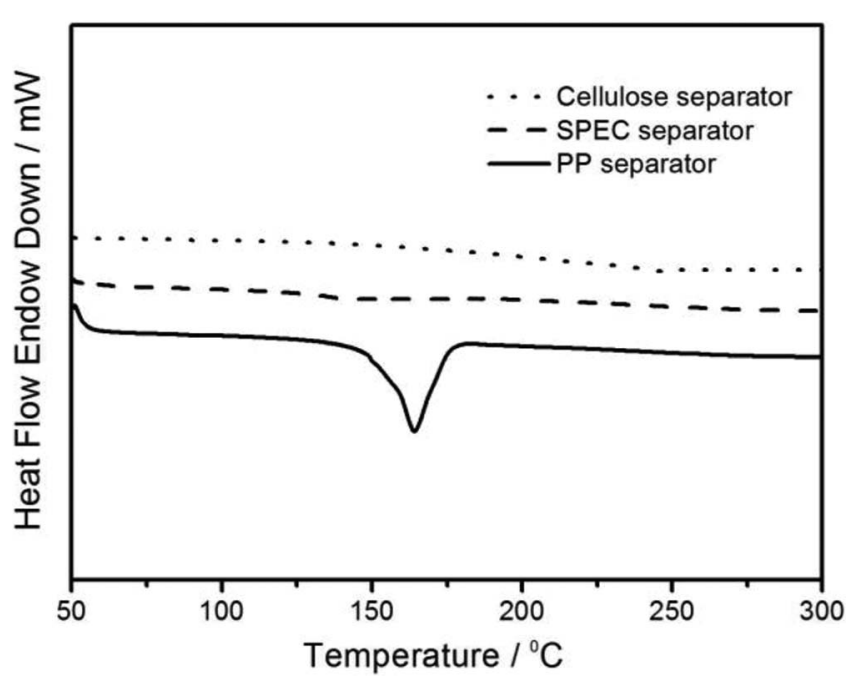

Figure 4. Differential scanning calorimetric (DSC) curves for the Celgard 2500 and dry SPEC separators.

exhibited diffraction peaks at $13.3^{\circ}, 19.5^{\circ}, 23^{\circ}, 32^{\circ}$ and $35.7^{\circ}$. The PVDF-HFP had diffraction peaks at $18.5^{\circ}, 20^{\circ}, 26.6^{\circ}$, and $38.9^{\circ}$, which corresponded to the crystallization phase of pure PVDF. ${ }^{31}$ This confirmed the partial crystallization of PVDF units in the copolymer and gave a semi-crystalline structure of PVDF-HFP. ${ }^{32,33}$ The three diffraction peaks occurred at $12.2^{\circ}, 20.1^{\circ}$ and $21.6^{\circ}$ of cellulose nonwoven, which were the typical diffraction patterns of cellulose II. ${ }^{34}$ After the addition of polymer lithium salt (PLTB) into PVDF-HFP and then onto the cellulose nonwoven, the diffraction peaks of pure PLTB disappeared. The absence of crystalline PLTB and PVDF-HFP peaks indicated, to some extent, that these two phases were well compatible. This indicated that PLTB homogeneously dispersed in the PVDF-HFP exhibited an amorphous structure, which would facilitate dissociation and migration of $\mathrm{Li}^{+}$in the polymer matrix and enhance the ionic conductivity.

In order to investigate the thermal behavior of SPEC separators, the differential scanning calorimetry (DSC) curves of the PP (Celgard 2500) and SPEC separators were compared in Figure 4. The exothermic peak of Celgard 2500 at $160.4^{\circ} \mathrm{C}$ was related to the melting temperature of this separator, which meant that this separator would shrink and melt down above $160^{\circ} \mathrm{C}$. Whereas the SPEC separator displayed no obvious exothermic or endothermic peaks up to $300^{\circ} \mathrm{C}$, indicating that the SPEC separator possessed superior dimensionally thermal stability. Figure 5 showed that Celgard 2500 separator generated significant shrinkage after exposure to $150^{\circ} \mathrm{C}$ for $0.5 \mathrm{~h}$, while the dimensional change of SPEC separator appeared to be negligible. Hence, SPEC separator was expected to be a highly safe separator for lithium ion battery with requested thermal safety.

The flame retarding ability of the separators is greatly associated with the battery safety. The flame retarding testing was shown in Figure 6. When the pristine cellulose separator was set on fire, the separator caught fire rapidly (Figure 6b). This behavior was similar
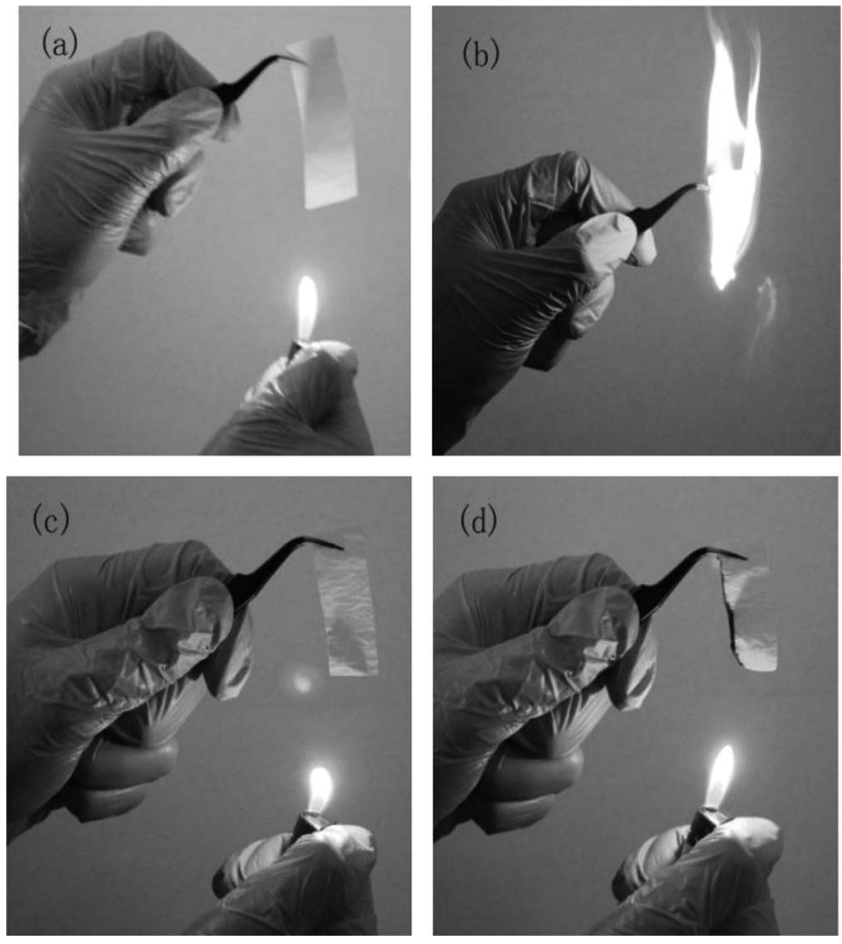

Figure 6. Flame retarding behaviors of the dry pristine cellulose separator $(a, b)$ and the dry SPEC separator $(c, d)$.

to the traditional polyolefin-based separators. In contrast, SPEC separator caught fire slowly and self-extinguished when the flame was removed (Figure 6d). A flame retarding ability was attributed to the synergetic effect of the boron component in the PLTB and PVDF-HFP, which were reported to be good flame retardants. The limiting oxygen index (LOI) of PP separator, cellulose separator and SPEC separator was $18 \%, 17 \%$ and $29 \%$. The higher LOI value of SPEC separator also demonstrated the better flame-retardancy. These properties enhance the safety of lithium-ion batteries when compared to the commercial polyolefin or cellulose separators.

Table I listed the thickness, porosity, air permeability, electrolyte uptake and ion conductivity of the PP separator and the cellulose-based separators. It was worth noting that the porosity of the SPEC separator (70\%) was fairly higher than that of PP separator (55\%). The Gurley value of the SPEC separator was $41.5 \mathrm{~s}$, which was much lower than that of the PP separator ( $235 \mathrm{~s}$ ). The ionic conductivity of electrolyte using SPEC separator was $1.78 \mathrm{mS} \mathrm{cm} \mathrm{cm}^{-1}$, which was significant higher than that of PP separator $\left(1.05 \mathrm{mS} \mathrm{cm}^{-1}\right)$. The activation energy of the SPEC separator, PP separator and Cellulose separators were calculated to be $16.86 \mathrm{~kJ} / \mathrm{mol}, 20.86 \mathrm{~kJ} / \mathrm{mol}$ and $20.19 \mathrm{~kJ} / \mathrm{mol}$, respectively. The activation energy of the SPEC separator was slightly lower than those of PP separator and Cellulose separators, which would be favorable for the ionic conductivity (Seen in Figure 7). It was deduced that the SPEC separator possessed higher porosity, improved ionic conductivity and (a)

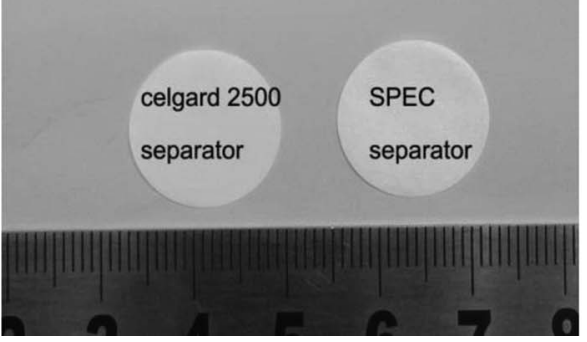

(b)

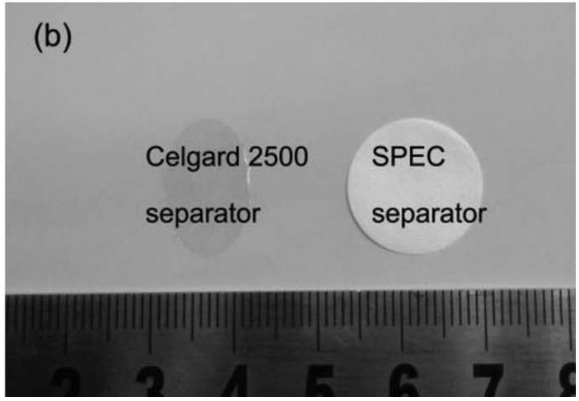

Figure 5. Thermal shrinkage photographs of Celgard 2500 separator and the dry SPEC separator (a) before and (b) after exposure to $150^{\circ} \mathrm{C}$ for $0.5 \mathrm{~h}$. 
Table I. Physical properties comparison of these separators.

\begin{tabular}{|c|c|c|c|c|c|c|}
\hline Sample & $\begin{array}{c}\text { Thickness } \\
(\mu \mathrm{m})\end{array}$ & $\begin{array}{c}\text { Porosity } \\
(\%)\end{array}$ & $\begin{array}{c}\text { Gurley value } \\
\text { (s) }\end{array}$ & $\begin{array}{c}\text { Electrolyte } \\
\text { uptake } \\
(\%)\end{array}$ & $\begin{array}{c}\text { Ionic } \\
\text { conductivity } \\
\left(\mathrm{mS} \mathrm{cm}^{-1}\right)\end{array}$ & $\begin{array}{c}\text { Lithium ion } \\
\text { transference } \\
\text { number } \\
\left(\mathrm{t}_{\mathrm{Li}}{ }^{+}\right)\end{array}$ \\
\hline Cellulose separator & 25 & 75 & 6.6 & 340 & 1.74 & 0.31 \\
\hline SPEC separator & 30 & 70 & 41.5 & 260 & 1.78 & 0.48 \\
\hline
\end{tabular}

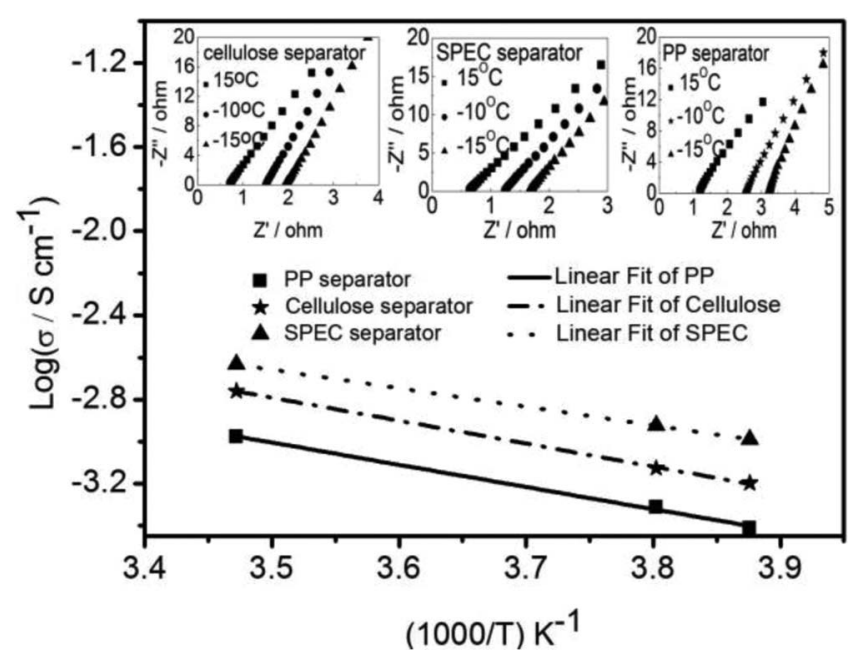

Figure 7. Impedance plots of the conductivity data at different temperatures and Arrhenius plots of the cellulose nonwoven, SPEC separator and PP separator saturated with $1 \mathrm{M} \mathrm{LiPF}_{6}$ organic electrolyte.

lower Gurley value, which would be beneficial to the rate capability of the battery. In contrast with the pristine cellulose nonwoven, although the dip-coated PLTB@PVDF-HFP alleviated the porosity to some extent, the SPEC separator after coating still possessed considerable porosity for holding sufficient liquid electrolyte in facilitating rapid ionic transportation. Moreover, the improvement of ionic conductivity was attributed to the addition of PLTB single ion conductor, which was beneficial to improving the performance at low temperature $\left(<-10^{\circ} \mathrm{C}\right)$ (Seen in Figure 7).

As the electrodes only exchange $\mathrm{Li}^{+}$with the electrolyte, a salt concentration gradient will be established during operation. The $\mathrm{Li}^{+}$depletion and anion overconcentration increase the polarization. Moreover, the mobile anions take part in undesirable side reactions at the electrodes, which also can directly affect the performance of batteries. ${ }^{1}$ Therefore it is necessary to increase $\mathrm{Li}^{+}$transference number to gain

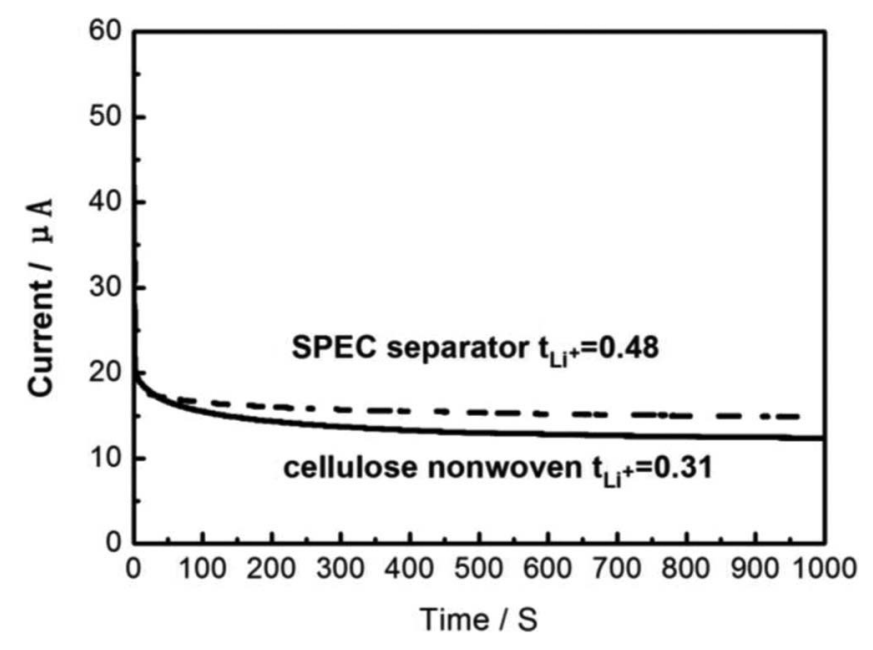

Figure 8. Chronoamperometry profiles for SPEC separator and cellulose separator.

good performance for lithium ion batteries. To further interpret the effective increment of the ionic conductivity of the SPEC separator, the $\mathrm{Li}^{+}$transference number was estimated by chronoamperometry (Figure 8). It was demonstrated that the SPEC separator possessed significantly increased $\mathrm{Li}^{+}$transference number of 0.48 when it was compared to that of the pristine one (0.31). The PLTB@PVDF-HFP membrane in liquid electrolyte behaved principally as a gel type of electrolyte with a high transfer number of $0.91 .^{28}$ Therefore, the cellulose composite separator after coating PLTB@PVDF-HFP exhibited higher lithium ion transference number in the liquid electrolytes. This higher $\mathrm{Li}^{+}$transference number would deliver higher $\mathrm{Li}^{+}$conductivity, which was critical factors in improving the battery rate capability.

It was shown in Figure 9 that the $1^{\text {st }}$ cycle and the $100^{\text {th }}$ cycle charge/discharge curves for the cells using the PP separator and the SPEC separator, respectively. The long plateau in the range of around $3.7 \mathrm{~V}$ in the first charge curve for each sample was attributed to the oxidation of $\mathrm{Co}^{3+}$ to $\mathrm{Co}^{4+}$, as shown in Figure 9a. The first irreversible
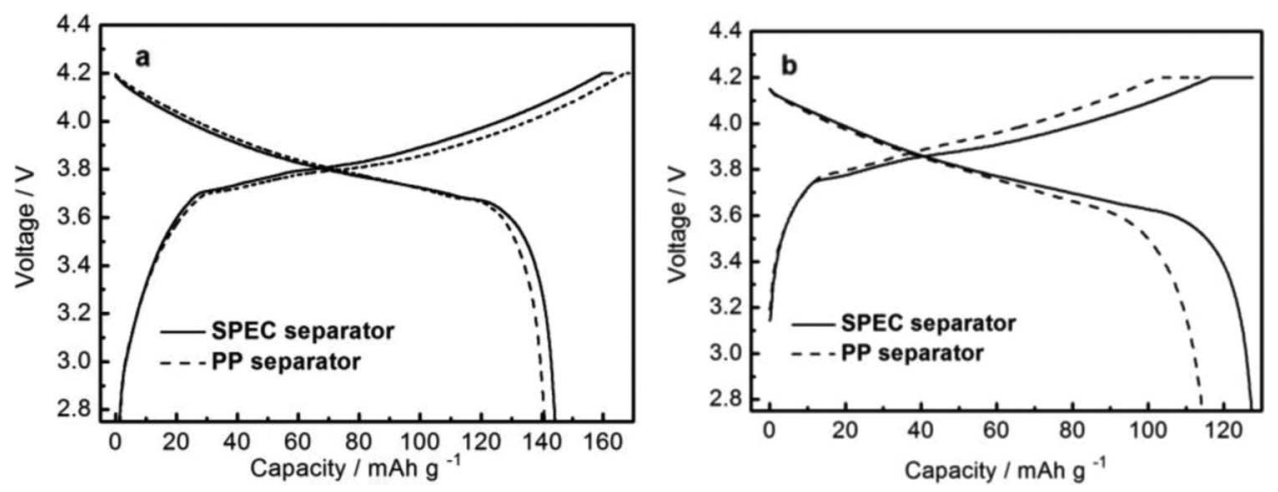

Figure 9. The $1^{\text {st }}$ cycle (a) and the $100^{\text {th }}$ cycle (b) charge/discharge curves for $\mathrm{LiCoO}_{2} /$ graphite cells using the SPEC separator and PP separator, respectively (charged/discharged at $0.5 \mathrm{C}$ ). 

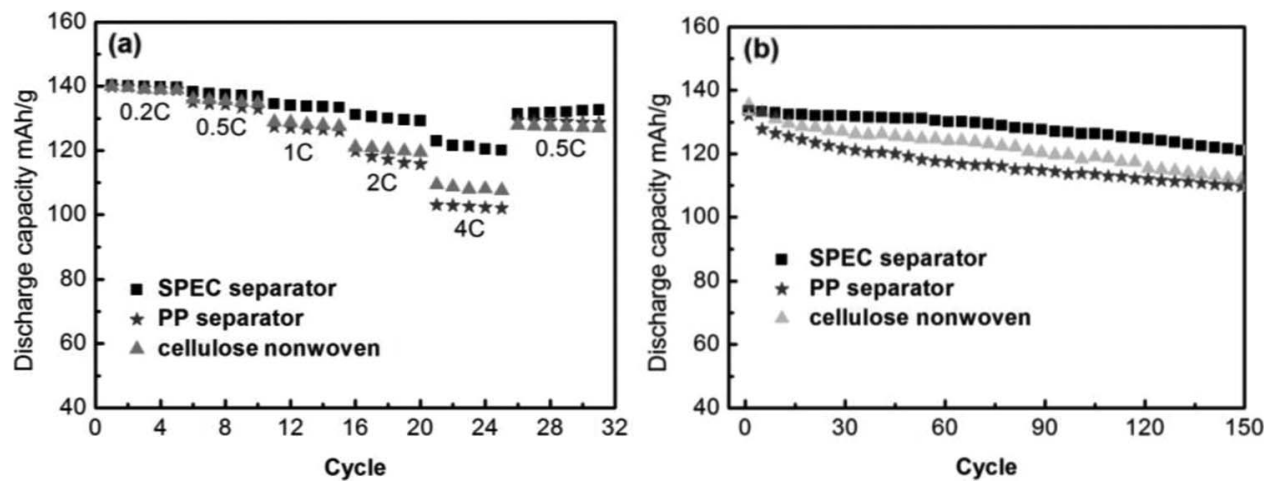

Figure 10. Rate capability (a) and cycle performance (b) of the cells using PP separator, pristine cellulose separator and SPEC separator.

specific capacity loss of the cell using the SPEC separator (19 mAh $\mathrm{g}^{-1}$ ) was much less than that of PP separator $\left(28 \mathrm{mAh} \mathrm{g}^{-1}\right)$, resulting in an increased initial coulombic efficiency from $83 \%$ to $88 \%$. This initial coulombic efficiency improvement may be attributed to the suppressed the sides reactions at the electrodes by the increased lithium ion transference number. Figure $9 \mathrm{~b}$ presented that the discharge capacity of the cell using SPEC separator $\left(127.5 \mathrm{mAh} \mathrm{g}^{-1}\right.$, normalized by the mass of $\mathrm{LiCoO}_{2}$ ) was higher than that using PP separator $\left(114.3 \mathrm{mAh} \mathrm{g}^{-1}\right)$ after 100 cycles, which indicated that the cell using cellulose composite separator exhibited superior cycling performance compared to the cell with PP separator.

The battery using the SPEC separator exhibited much better rate capability than the PP separator and pristine cellulose nonwoven at various discharge rates (seen in Figure 10a). The specific capacity of the battery using the pristine cellulose nonwoven, PP separator and SPEC separator was $136 \mathrm{mAh} \mathrm{g}^{-1}, 135 \mathrm{mAh} \mathrm{g}^{-1}$ and $138 \mathrm{mAh} \mathrm{g}^{-1}$ at $0.5 \mathrm{C}$, respectively, and remained $108 \mathrm{mAh} \mathrm{g}^{-1}, 102 \mathrm{mAh} \mathrm{g}^{-1}$ and $125 \mathrm{mAh} \mathrm{g}^{-1}$ at $4 \mathrm{C}$, respectively. It was obvious that the enhanced composite separator performed the best rate capability than the other two separators. This was undoubtedly attributed to the improved $\mathrm{Li}^{+}$ transference number of the SPEC separator which contributed to the remarkably higher ionic conductivity and much less polarization. The cyclability of the cell with SPEC separator was displayed in Figure 10b at charge/discharge rate of $0.5 \mathrm{C}$. The obtained discharge capacity after 150 cycles was around $120.8 \mathrm{mAh} \mathrm{g}^{-1}$ indicative of capacity retention about $90 \%$, which was significantly higher than $83 \%$ of PP separator. It was manifested that the SPEC separator exhibited better cycling performance than that of PP separator and pristine cellulose nonwoven.

\section{Conclusions}

In summary, it was demonstrated that the SPEC separator possessed excellent flame retardant performance, which would greatly enhance the safety of lithium-ion batteries. The lithium batteries using composite separators exhibited superior rate capability and favorable cycling performance compared to those batteries using PP and pristine cellulose nonwoven. The improved electrochemical performances were ascribed to an improved lithium ion transference number resulting from the coating layer of single-ion polymer electrolyte. Therefore, the SPEC composite separator would be a very promising alternative separator for the high performance lithium ion batteries.

\section{Acknowledgment}

This work was supported by National Natural Science Foundation of China (grant No. 21344003), Strategic Priority Research Program of the Chinese Academy of Sciences (grant No. XDA09010105),
Natural Science Foundation of Shandong Province (grant No. ZR2013FZ2001) and Key Technology Research Projects of Qingdao (grant No. 12-4-1-24-gx and13-4-1-10-gx).

\section{References}

1. J. M. Tarascon and M. Armand, Nature, 414, 359 (2001).

2. V. Etacheri, R. Marom, R. Elazari, G. Salitra, and D. Aurbach, Energy Environ. Sci., 4, 3243 (2011).

3. M. Armand and J. M. Tarascon, Nature, 451, 652 (2008).

4. B. Dunn, H. Kamath, and J. M. Tarascon, Science, 334, 928 (2011).

5. N. Kamaya, K. Homma, Y. Yamakawa, M. Hirayama, R. Kanno, M. Yonemura, T. Kamiyama, Y. Kato, S. Hama, K. Kawamoto, and A. Mitsui, Nat. mater, 10, 682 (2011).

6. H. Li, Z. X. Wang, L. Q. Chen, and X. J. Huang, Adv. Mater, 21, 4593 (2009).

7. S. S. Zhang, J. Power Sources, 164, 351 (2007).

8. G. L. Cui, L. Gu, L. J. Zhi, N. Kaskhedikar, P. A. van Aken, K. Mullen, and J. Maier, Adv. Mater., 20, 3079 (2008).

9. B. Koo, H. Kim, Y. Cho, K. T. Lee, N. S. Choi, and J. Cho, Angew. Chem. Int. Ed., 51, 8762 (2012).

10. F. Croce, M. L. Focarete, J. Hassoun, I. Meschini, and B. Scrosati, Energ. Environ. Sci., 4, 921 (2011).

11. J. Liu, J. G. Zhang, Z. G. Yang, J. P. Lemmon, C. Imhoff, G. L. Graff, and B. Schwenzer, Adv. Funct. Mater, 23, 929 (2013).

12. W. Jiang, Z. H. Liu, Q. S. Kong, J. H. Yao, C. J. Zhang, P. X. Han, and G. L. Cui Solid State Ionics, 232, 44 (2013).

13. Y. S. Zhu, S. Y. Xiao, Y. Shi, Y. Q. Yang, Y. Y. Hou, and Y. P. Wu, Adv. Energ. Mater, 4, 1300647 (2014)

14. M. H. Ryou, Y. M. Lee, J. K. Park, and J. W. Choi, Adv. Mater, 23, 3066 (2011)

15. J. Hassoun, S. Panero, P. Reale, and B. Scrosati, Adv. Mater, 21, 4807 (2009).

16. Z. Cai, Y. Liu, S. Liu, L. Li, and Y. Zhang, Energ. Environ. Sci., 5, 5690 (2012).

17. H. Lee, M. Alcoutlabi, J. V. Watson, and X. W. Zhang, J. Appl. Polym. Sci., 129, 1939 (2013).

18. K. S. Liu, X. Yao, and L. Jiang, Chem. Soc. Rev., 39, 3240 (2010).

19. Y. S. Zhu, F. X. Wang, L. L. Liu, S. Y. Xiao, Y. Q. Yang, and Y. P. Wu, Sci. Rep., 3, 3187 (2013).

20. X. H. Zhou, L. P. Yue, J. J. Zhang, Q. S. Kong, Z. H. Liu, J. H. Yao, and G. L. Cui, J. Electrochem. Soc., 160, A1341 (2013)

21. R. Bouchet, Nat. Mater, 12, 452 (2013).

22. K. Xu, Chem. Rev., 104, 4303 (2004).

23. E. L. Jackson and C. S. Hudson, J. Am. Chem. Soc., 59, 2049 (1937).

24. L. Jabbour, R. Bongiovanni, D. Chaussy, C. Gerbaldi, and D. Beneventi, Cellulose, 20, 1523 (2013).

25. J. J. Zhang, Z. H. Liu, Q. S. Kong, C. J. Zhang, S. P. Pang, L. P. Yue, X. J. Wang, J. H. Yao, and G. L. Cui, ACS Appl. Mater. Interfaces, 5, 128 (2013).

26. L. Jabbour, M. Destro, C. Gerbaldi, D. Chaussy, N. Penazzi, and D. Beneventi, J. Mater. Chem., 22, 3227 (2012).

27. J. Maier, Angew. Chem. Int. Ed., 52, 4998 (2013).

28. X. J. Wang, Z. H. Liu, C. J. Zhang, Q. S. Kong, J. H. Yao, P. X. Han, W. Jiang, H. X. Xu, and G. L. Cui, Electrochim. Acta, 92, 132 (2013).

29. J. M. Tarascon, A. S. Gozdz, C. Schmutz, F. Shokoohi, and P. C. Warren, Solid State Ionics, 86-88, 49 (1996).

30. J. Evants, C. A. Vincent, and P. G. Bruce, Polymer, 28, 2324 (1987).

31. D. Saika and A. Kumar, Electrochim. Acta, 49, 2581 (2004).

32. A. M. Stephan, K. S. Nahm, M. A. Kulandainathan, G. Ravi, and J. Wilson, Eur. Polym. J., 42, 1728 (2006).

33. O. Padmaraj, M. Venkateswarlu, and N. Satyanarayana, Ionics, 19, 1835 (2013).

34. Y. P. Liu and H. Hu, Fiber. Polym., 9, 735 (2008). 